\title{
Survey reveals caries knowledge gap
}

New data published by the Oral Health Foundation and Colgate-

Palmolive have disclosed a concerning lack of knowledge of dental caries among patients. ${ }^{1}$ The Oral Health Foundation is now calling on dental professionals to help raise awareness of dental caries amongst patients in order to improve the oral health of the nation.

Dental caries is estimated to affect around 2.3 billion people globally. ${ }^{2}$ In the UK, it is estimated that just under one-in-three adults suffer from caries ${ }^{3}$ - a problem which the charity believes has been exacerbated during the pandemic.

Despite its prevalence, many patients remain unaware of the circumstances that could lead to them being at higher risk or understand how they can prevent the disease from occurring.

As part of a new nationwide omnibus survey into dental caries and fluoride [sample size $=2,008$ ], one-in-three $(33 \%)$ were unable to identify 'brushing teeth' as an action that could prevent the disease.

Furthermore, over half of respondents (54\%) did not associate 'regular dental appointments' to lower caries risk and more than one-in-four (26\%) did not know that 'high carbohydrate' diets can be responsible for higher caries risk. ${ }^{3}$

There was also a lack of awareness around the other major risk factors of caries, including older age, dry mouth, and having a history of oral health restorations.

The survey's findings are part of the Oral Health Foundation's 'The Truth About Tooth Decay' - an online hub, created in partnership with Colgate-Palmolive. The platform hosts educational material for patients around dental caries. The site also includes a dedicated area for dental professionals with tips and tools for educating patients about the symptoms and risk factors of dental caries.

Dr Ben Atkins, President of the Oral Health Foundation, believes the results of this survey have highlighted a knowledge gap that needs to be addressed sooner rather than later.

Dr Atkins said: 'Dental professionals are in a great position to help patients of all ages better understand their oral health. This education cannot only be done in the dental chair, it can also be done digitally on social media and through e-communications. The latter has become increasingly important given the restrictions from the pandemic. Digital learning is likely to play a key role in delivering the prevention aspects of the new dental contract'.

For more information, and to view 'The Truth About Tooth Decay' online hub, visit www.dentalhealth.org/ thetruthabouttoothdecay.

\section{References}

1. Oral Health Foundation and Colgate-Palmolive. Dental Caries Awareness Survey. UK: Broadcast Revolution, 2021.

2. World Health Organisation. Sugar and dental caries. 2017. Available at: https:// www.who.int/oral_health/publications/sugars-dental-caries-keyfacts/ en/\#:\%7E:text=1t\%20is\%20also\%20the\%20most,by\%20avoiding\%20dietary $\% 20$ free\%20sugars (accessed 28 May 2021).

3. NHS. The Information Centre for Health and Social Care. 2. Disease and related disorders - a report from the Adult Dental Health Survey 2009. 24 March 2011 Available at: https://files.digital.nhs.uk/publicationimport/pub01xxx/pub01086/ adul-dent-heal-surv-summ-them-the2-2009-rep4.pdf (accessed 28 May 2021). 